\title{
Periapical health related to the quality of coronal restorations and root fillings in Turkish population
}

Sibel Koçak, DDS, PhD, ${ }^{a}$ Baran Can Sağlam, DDS, PhD, ${ }^{a}$ Mustafa Murat Koçak, DDS, PhD, ${ }^{a}$ Fürüzan Köktürk, DDS, Phd ${ }^{\mathrm{b}}$

${ }^{a}$ Bülent Ecevit University, Faculty of Dentistry, Department of Endodontics, Zonguldak, Turkey.

${ }^{\mathrm{b}}$ Bülent Ecevit University, Faculty of Medicine, Department of Biostatistics, Zonguldak, Turkey.

Received: 14 December 2012

Accepted: 18 February 2013

\begin{abstract}
Objectives: The aim of the present study was to evaluate the quality of root canal treatments and coronal restorations investigating their influence on the periapical status of endodontically-treated teeth in a Turkish population based on radiographic examination.

Materials and Methods: The study included 583 patients referred for routine dental care. A total of 1125 endodontically treated teeth were examined with panoramic radiographs. The quality of root canal fillings and coronal restorations were evaluated according to the criteria determined by Gündüz et al., which were slightly modified from those described by De Moor et al. Apical status was assessed by the Periapical Index (PAI) scores.

Results: Out of 1125 endodontically treated teeth, 539 were classified as healthy and 586 as displaying apical periodontitis. Of these 539 subjects, 389 teeth had received quality endodontic treatment. Of 586 teeth with apical periodontitis, 500 had poor endodontic treatment. Four hundred and seventy-five teeth had adequate root canal fillings. Of these teeth, 389 were classified as healthy. Of the 666 teeth with adequate restoration, apical region was classified as healthy for 410 subjects. For the 388 teeth with both adequate coronal restorations and root canal fillings, the success rate was $85.3 \%$. For the 372 teeth with both inadequate coronal restorations and root canal fillings, the success rate was $18.8 \%$.
\end{abstract}

Conclusions: The quality of root fillings in the population living in the back country of Turkey is in general below the acceptable standard and requires substantial improvement.

Keywords: Apical periodontitis, panoramic radiographs, periapical status, root canal treatment.

\section{INTRODUCTION}

Apical periodontitis (AP) has been reported to be a widespread disease among adult populations, with a range of prevalence between $27 \%$ and $70 \%$. According to previous investigations, poor quality of root fillings is one of the main features associated with the presence of AP . 2,4 Although many studies have focused on the quality of root canal

Sibel KOÇAK,

Department of Endodontics,

Faculty of Dentistry,

Bülent Ecevit University,

Kozlu 67600, Zonguldak, Turkey.

Fax: +90-372-2613403

e-mail: sibel_tazegul@yahoo.com fillings, Ray and Trope reported that the absence of periodontitis was more common among teeth with good coronal restorations. ${ }^{5}$ The results of their study revealed that coronal leakage of bacteria and bacterial products along the margin of the inadequate restoration may cause infection of endodontically-treated teeth. The quality of coronal restoration and coronal leakage of obturated canals, as well as the quality of root canal fillings, have become points of particular interest. Previous studies have reported that the coronal restoration is the primary barrier to avoid leakage of a filled root canal. ${ }^{6,7}$ 
The aim of the present study was to evaluate the quality of root canal treatments and coronal restorations investigating their influence on the periapical status of endodontically-treated teeth in a Turkish population based on radiographic examination.

\section{MATERIALS AND METHODS}

The study included 583 patients: 277 males $(47.5 \%)$ and 306 females $(52.5 \%)$, who had been referred to the University of Bülent Ecevit, Department of Oral Diagnosis and Radiology for routine dental care. The main criterion for inclusion in the study was the availability of panoramic radiograph. Panoramic radiographs with poor image quality were excluded from the study. Teeth without permanent restorations and patients younger than 18 years old at the time of radiography were excluded. A total of 1125 endodonticallytreated teeth were examined. All radiographs were taken and processed in the same department between 2010 and 2011. Gendex Orthoralix 9200 digital panoramic X-ray machine (Gendex Dental Systems, Des Plaines, IL, US) was used to take radiographs.

Radiographs were evaluated by two endodontists who each had over 5 years of clinical experience. Both examiners were calibrated. As part of the calibration phase, the study methodology was explained to the examiners. To minimize the potential for discrepant results, they also familiarized themselves with the scores they should attribute to the radiographic images and the established evaluation method for the study. Panoramic radiographs were examined independently by both observers. Additionally, panoramic radiographs including two hundred teeth were assessed to calibrate the examiners, and interexaminer agreement was determined by Cohen's kappa (kappa=0.86). The radiographs were observed using an X-ray viewer with 2 times magnification. The room was darkened to control the surrounding light for the best radiographic contrast.

The quality of root canal fillings and coronal restorations were evaluated according to the criteria determined by Gündüz et al., which were slightly modified from those described by De Moor et al.. ${ }^{2,8}$ Parameters were as follows:

Quality of root filling:

- Adequate endodontic treatment: All canals obturated without voids. Root canal filling 0-2 $\mathrm{mm}$ short from the radiographic apex.

- Inadequate endodontic treatment: Root canal filling ending more than $2 \mathrm{~mm}$ short of the radiographic apex or overfilled. Root canal filling with inadequate density, voids, unfilled canals, or poor condensation.

Quality of coronal restoration:

- Adequate: Intact restoration with good margin adaptation and no signs of recurrent carries.

- Inadequate: Restoration with overhangs, open margins, and recurrent carries.

Apical status was assessed by the Periapical Index (PAI) scores proposed by Ørstavik et al. ${ }^{9}$ Scores were as follows:

1. Normal periapical structures

2. Small changes in bone structure

3 . Changes in the bone structure with little mineral loss

4. Periodontitis with well-defined radiolucent area

5. Severe periodontitis with exacerbating features

PAI 1, normal width of permanent ligament space and normal appearance of surrounding bone, was defined as healthy periapex. All other PAI scores were evaluated as apical periodontitis.

Statistical analysis was performed with SPSS 18.0 software (SPSS, Inc., Chicago, IL, US). Variables were expressed as frequencies and percentages. Categorical variables were compared by using Pearson's Chi-square test. 


\section{RESULTS}

On the basis of the PAI scoring system, out of 1125 endodontically-treated teeth, 539 were classified as healthy and 586 teeth as AP. Of 539 healthy subjects, 389 teeth had received good endodontic treatment and 150 teeth had inadequate root fillings. Of 586 teeth with AP, 500 had poor endodontic treatment; however, 86 teeth with adequate root fillings also showed criteria of AP.

Four hundred and seventy-five teeth had adequate root canal fillings. Of these teeth, 389 were classified as healthy and 86 were classified as AP. Six hundred and fifty teeth had inadequate root canal fillings. Of these teeth, 150 were classified as healthy and 500 were classified as AP. The difference between the two groups was statistically significant $(p<0.001)$. Table 1 provides an overview of the relationship between the quality of root canal filling and periapical status.

Six hundred and sixty-six teeth had adequate coronal restorations, whereas 459 teeth had inadequate coronal restorations. Of the 666 teeth with adequate restoration, apical region was classified as healthy for 410 subjects and recorded as AP for 256. Of the teeth with the score PAI $1(\mathrm{~N}=$ 539), 410 subjects had adequate restorations whereas 129 had inadequate restorations. The difference between the two groups was statistically significant $(p<0.001)$. Table 2 gives an overview of the relationship between the quality of restoration and periapical status.

For the 388 teeth with both adequate coronal restorations and root canal fillings, the number of healthy teeth was 331, whilst only 57 displayed radiographic signs of AP. The group with adequate coronal restorations and inadequate root canal fillings consisted of 278 teeth. Eighty teeth were healthy, and 198 had signs of AP. Of the 87 teeth with inadequate coronal restorations and adequate root canal fillings, 58 teeth were healthy and 29 had AP. For the 372 teeth with both inadequate coronal restorations and root canal fillings, the number of healthy subjects was 70, whereas 302 subjects had AP. Table 3 gives an overview of the relationship between the quality of root canal filling, quality of restoration, and periapical status.

Table 1. The relationship between the quality of root canal filling and periapical status.

\begin{tabular}{|c|c|c|c|}
\hline $\begin{array}{c}\text { Root canal } \\
\text { filling }\end{array}$ & N & PAI 1 & PAI 2-5 \\
\hline \hline Adequate & 475 & $389(81.9 \%)$ & $86(18.1 \%)$ \\
Inadequate & 650 & $150(23.1 \%)$ & $500(76.9 \%)$ \\
& & & \\
\hline
\end{tabular}

Table 2. The relationship between the quality of coronal restoration and periapical status.

\begin{tabular}{|c|c|c|c|}
\hline Restoration & $\mathrm{N}$ & PAI 1 & PAI 2-5 \\
\hline \hline Adequate & 666 & $\mathbf{4 1 0}(61.6 \%)$ & $256(38.4 \%)$ \\
Inadequate & 459 & $129(28.1 \%)$ & $330(71.9 \%)$ \\
\hline
\end{tabular}

Table 3. The relationship between the quality of root canal filling, quality of restoration, and periapical status.

\begin{tabular}{|c|c|c|c|}
\hline $\begin{array}{l}\text { Quality of } \\
\text { restoration-root } \\
\text { canal filling }\end{array}$ & $\mathbf{N}$ & PAI 1 & PAI 2-5 \\
\hline $\begin{array}{l}\text { Adequate- } \\
\text { Adequate } \\
\text { Adequate- } \\
\text { Inadequate }\end{array}$ & $\begin{array}{r}388 \\
278 \\
87\end{array}$ & $\begin{array}{c}331 \\
(85.3 \%) \\
80 \\
(28.8 \%)\end{array}$ & $\begin{array}{c}57 \\
(14.7 \%) \\
198 \\
(71.2 \%)\end{array}$ \\
\hline $\begin{array}{l}\text { Inadequate- } \\
\text { Adequate } \\
\text { Inadequate- } \\
\text { Inadequate }\end{array}$ & 372 & $\begin{array}{c}58 \\
(66.7 \%) \\
70 \\
(18.8 \%)\end{array}$ & $\begin{array}{c}29 \\
(33.3 \%) \\
302 \\
(81.2 \%)\end{array}$ \\
\hline
\end{tabular}




\section{DISCUSSION}

Cross-sectional studies are used to evaluate the relationship between quality of treatment and health of teeth in populations. However, the data consisting of patients visiting a dental school does not represent a random sample of a population, although it may be somewhat useful in reflecting the overall population. The main disadvantage of a cross-sectional study is the difficulty of determining whether a periapical lesion is healing or not, because of the lack of information about when the endodontic treatments or restorations were performed. ${ }^{10}$ On the other hand, obtaining a large sample size and a random selection are advantages of this method. ${ }^{6}$

This is the first study evaluating the quality of coronal and root fillings in the back country of Turkey. To our knowledge, such data have not been collected previously either in minor cities or in the West Black Sea region of Turkey. This information is necessary to assess the effectiveness of dental care, as well as to compare the quality of treatment between major and minor cities and to help with the planning and development of future dental services, including the training of dental personnel. Previous studies reported varying levels of prevalence of AP, ranging from $37.99 \%$ to $67.9 \%$ in Turkey. ${ }^{8,11,12}$ Our findings were comparable with the previous results. However, the previous studies evaluating the incidence of AP in the Turkish population were performed in major cities. Because most dental specialists are centered in major cities, dental care is more sophisticated in these locations. ${ }^{12}$ Therefore, it is questionable whether the patient population evaluated in the previous studies can be seen as representative of the Turkish population in general.

In the past studies, the methods evaluating the quality of root fillings and periapical status differed, but all used radiographs. In the detection of periapical changes with high sensitivity, a survey must include periapical, panoramic, and bite-wing radiographs. ${ }^{13}$ However, although these three techniques are more precise and sensitive, combining them has the disadvantage of exposing patients to over-radiation. Ahlqwist et al. stated that the use of panoramic radiography in epidemiologic studies of dental health was acceptable. ${ }^{4}$ They reported a high specificity and sensitivity for the detection of periapical pathology on panoramic radiographs compared with full-mouth surveys. Aside from this utilization, using panoramic radiographs may allow us to compare our results with many past studies that used the same method.

Previous studies accepted PAI > 2 scores for apical periodontitis. The score PAI 2 describes small changes in bone structure. Gündüz et al. accepted only the score PAI 1 as healthy. In our study, the same criteria were used for classification of healthy and apical periodontitis groups. ${ }^{8}$ Because of the questionable prognosis of even small changes in bone structures, scores higher than PAI 1 were accepted as signifying apical periodontitis in our study.

The prevention of coronal leakage influences the long-term success of endodontic treatment positively. Ray and Trope concluded that periapical lesions existed less frequently in teeth with good coronal restorations. ${ }^{5}$ Our findings are similar to those of other investigations that found a significant correlation between the radiographic quality of the coronal restoration and the periapical status of endodontically-treated teeth. $5,15,16$

The results of our study showed that healthy periapical scores were significantly higher in teeth with good endodontic treatment regardless of the type of restoration. Our results were supported by those of previous studies that indicated an adequate root filling had a more substantial impact on the outcome of the treatment than the quality of coronal restoration 
did. ${ }^{17}$ Only $42.2 \%$ of the roots in our study fulfilled the criteria of the European Society of Endodontology for an acceptable root canal filling, and of these teeth, $18.1 \%$ had AP. ${ }^{18}$ These results are similar with those of some studies of European populations, which have shown that approximately $10-46 \%$ of the teeth with adequate root fillings had AP. ${ }^{15,16,19-23}$ In the present study, the success rate of adequate root canal treatments was significantly higher than inadequate canal treatments.

The individual evaluations of coronal restorations and root canal fillings showed that both factors had significant effects on periapical health. When the quality of the root fillings and the quality of coronal restoration were combined, an even more pronounced pattern emerged. In our opinion, evaluation of the periapical status of an endodontically-treated tooth should include and investigate both the quality of coronal restoration and root canal filling. Previous studies demonstrated that the prognosis of an endodontically-treated tooth is positively correlated with the technical quality of the root canal filling and coronal restoration. ${ }^{6,16}$ Kirkevang et al. stated that the combination of inadequate root canal fillings and coronal restorations were associated with an increased incidence of $\mathrm{AP}^{16}$ This result was also supported by Hommez et al. who demonstrated that a well-sealed coronal restoration and a well-performed root canal treatment were both important for the overall success of endodontic treatment. In the present study, the high success rate was remarkable for the teeth with both adequate coronal restorations and root canal fillings. ${ }^{10}$ Our results clearly demonstrated that both factors were indispensible and could not be discussed separately.

\section{CONCLUSION}

Within the limitations of this study, the results confirm the findings of other studies that found that coronal restoration and the quality of the root canal treatment were both key factors for prognosis of a tooth. In conclusion, the quality of root fillings in the population living in the back country of Turkey is in general below the acceptable standard and requires substantial improvement.

\section{REFERENCES}

1. Kabak Y, Abbott PV. Prevalence of apical periodontitis and the quality of endodontic treatment in an adult Belarusian population. Int Endod J 2005;38:238-245.

2. De Moor RJ, Hommez GM, De Boever JG, Delme KI, Martens GE. Periapical health related to the quality of root canal treatment in a Belgian population. Int Endod $\mathrm{J}$ 2000;33:113-120.

3. Figdor D. Apical periodontitis: a very prevalent problem. Oral Surg Oral Med Oral Pathol Oral Radiol Endod 2002;94:651-652.

4. Kirkevang LL, Wenzel A. Risk indicators for apical periodontitis. Community Dent Oral Epidemiol 2003;31:59-67.

5. Ray HA, Trope M. Periapical status of endodontically treated teeth in relation to the technical quality of the root filling and the coronal restoration. Int Endod J 1995;28:1218.

6. Siqueira JF, Jr., Rocas IN, Alves FR, Campos LC. Periradicular status related to the quality of coronal restorations and root canal fillings in a Brazilian population. Oral Surg Oral Med Oral Pathol Oral Radiol Endod 2005;100:369-374.

7. Torabinejad M, Ung B, Kettering JD. In vitro bacterial penetration of coronally unsealed endodontically treated teeth. J Endod 1990;16:566569.

8. Gunduz K, Avsever H, Orhan K, Demirkaya K. Cross-sectional 
evaluation of the periapical status as related to quality of root canal fillings and coronal restorations in a rural adult male population of Turkey. BMC Oral Health 2011;11:20.

9. Ørstavik D, Kerekes K, Eriksen HM. The periapical index: a scoring system for radiographic assessment of apical periodontitis. Endod Dent Traumatol 1986;2:20-34.

10. Hommez GM, Coppens CR, De Moor RJ. Periapical health related to the quality of coronal restorations and root fillings. Int Endod $\mathbf{J}$ 2002;35:680-689.

11. Ozbas H, Asci S, Aydin $\mathrm{Y}$. Examination of the prevalence of periapical lesions and technical quality of endodontic treatment in a Turkish subpopulation. Oral Surg Oral Med Oral Pathol Oral Radiol Endod 2011;112:136-142.

12. Sunay H, Tanalp J, Dikbas I, Bayirli G. Cross-sectional evaluation of the periapical status and quality of root canal treatment in a selected population of urban Turkish adults. Int Endod J 2007;40:139-145.

13. Muhammed AH, Manson-Hing LR, Ala B. A comparison of panoramic and intraoral radiographic surveys in evaluating a dental clinic population. Oral Surg Oral Med Oral Pathol 1982;54:108-117.

14. Ahlqwist M, Halling A, Hollender L. Rotational panoramic radiography in epidemiological studies of dental health. Comparison between panoramic radiographs and intraoral full mouth surveys. Swed Dent J 1986;10:73-84.

15. Dugas NN, Lawrence HP, Teplitsky PE, Pharoah MJ, Friedman S. Periapical health and treatment quality assessment of root-filled teeth in two Canadian populations. Int Endod J 2003;36:181-192.
16. Kirkevang LL, Ørstavik D, HörstedBindslev P, Wenzel A. Periapical status and quality of root fillings and coronal restorations in a Danish population. Int Endod J 2000;33:509515.

17. Segura-Egea JJ, Jimenez-Pinzon A, Poyato-Ferrera M, Velasco-Ortega E, Rios-Santos JV. Periapical status and quality of root fillings and coronal restorations in an adult Spanish population. Int Endod J 2004;37:525530.

18. European Society of Endodontology. Quality guidelines for endodontic treatment: consensus report of the European Society of Endodontology. Int Endod J 2006;39:921-930.

19. Eriksen HM, Bjertness E, Ørstavik D. Prevalence and quality of endodontic treatment in an urban adult population in Norway. Endod Dent Traumatol 1988;4:122-126.

20. Eriksen HM, Bjertness E. Prevalence of apical periodontitis and results of endodontic treatment in middle-aged adults in Norway. Endod Dent Traumatol 1991;7:1-4.

21. De Cleen MJ, Schuurs AH, Wesselink PR, Wu MK. Periapical status and prevalence of endodontic treatment in an adult Dutch population. Int Endod J 1993;26:112119.

22. Saunders WP, Saunders EM, Sadiq J, Cruickshank E. Technical standard of root canal treatment in an adult Scottish sub-population. Br Dent J 1997;182:382-386.

23. López-López J, Jané-Salas E, Estrugo-Devesa A, CastellanosCosano L, Martín-González J, Velasco-Ortega E, Segura-Egea JJ. Frequency and distribution of rootfilled teeth and apical periodontitis in an adult population of Barcelona, Spain. Int Dent J 2012;62:40-46. 